\title{
Síndrome de fournier: ações do enfermeiro, uma revisão literária
}

RESUMO | A Síndrome de Fournier é um processo infeccioso severo que atinge os tecidos moles com avanço acelerado, possui etiologia polimicrobiana, com presença predominante de micro-organismos aeróbicos e anaeróbicos gram positivos e negativos. A finalidade deste trabalho é identificar por meio de revisão bibliográfica o conhecimento e atuação do enfermeiro sobre a síndrome de founier para que a sistematização de enfermagem seja executada de uma forma eficaz, prestando um atendimento eficiente ao paciente. Foi realizada revisão literária entre os anos de 2009 a 2019. Foram enfatizados a aplicabilidade da sistematização da assistência de enfermagem no tratamento, diagnóstico, complicações de acordo com a atuação do enfermeiro. Verificou-se que o tratamento incluiu a antibioticoterapia de amplo espectro e a cobertura mais indicada e utilizada foi à papaína. A oxigenoterapia hiperbárica foi aliada ao tratamento, porém questionada por alguns autores. Conclui- se que, de acordo com a revisão bibliográfica, não há dados publicados suficientes para realizar a análise.

Palavras-chaves: Síndrome Fournier; Necrosante; Enfermagem; Ferida.

ABSTRACT | Fournier syndrome is a severe infectious process that affects fast-advancing soft tissues, has a polymicrobial etiology, with predominant presence of aerobic and anaerobic gram positive and negative microorganisms. The purpose of this study is to identify through literature review the knowledge and performance of nurses about the Fournier syndrome so that nursing systematization is performed effectively, providing efficient care to the patient. A literature review was conducted between 2009 and 2019. The applicability of the systematization of nursing care in the treatment, diagnosis, and complications according to the nurse's performance was emphasized. The treatment was found to include broad spectrum antibiotic therapy and the most appropriate coverage used was papain. Hyperbaric oxygen therapy was combined with treatment but questioned by some authors. It is concluded that, according to the literature review, there are not enough published data to perform the analysis.

Keywords: Syndrome Fournier; Necrotizing; Nursing; Wound.

RESUMEN | El síndrome de Fournier es un proceso infeccioso severo que afecta los tejidos blandos con un progreso acelerado, tiene una etiología polimicrobiana, con una presencia predominante de microorganismos gram positivos y negativos aerobios y anaerobios. El objetivo de este trabajo es identificar, mediante una revisión bibliográfica, el conocimiento y el desempeño de las enfermeras sobre el síndrome de Founier para que la sistematización de enfermería se realice de manera efectiva, brindando una atención eficiente al paciente. Se realizó una revisión literaria entre los años 2009 a 2019. Se enfatizó la aplicabilidad de la sistematización de la atención de enfermería en el tratamiento, diagnóstico, complicaciones según el desempeño de la enfermera. Se descubrió que el tratamiento incluía antibióticos de amplio espectro y la cobertura más indicada y utilizada fue la papaína. La oxigenoterapia hiperbárica se combinó con el tratamiento, pero algunos autores la cuestionaron. Se concluye que, según la revisión de la literatura, no hay suficientes datos publicados para realizar el análisis.

Descriptores: Síndrome Fournier; Necrotizante; Enfermería; Herida.

Everton da Silva Freitas

INTRODUÇÃO

Discente de Enfermagem. Faculdade LS, Brasília, DF.

\section{Franciédina de Sousa Duarte}

Discente de Enfermagem. Faculdade LS, Brasília, DF.

\section{Kellen Maria da Silva Maia Araújo}

Discente de Enfermagem. Faculdade LS, Brasilia, DF.

\section{Janine Brixner}

Docente de Enfermagem. Mestre em Educação. Faculdade LS, Brasília, DF.

\section{Éder Alves Marques}

Docente de Enfermagem. Doutor e Mestre em Ciências. Faculdade LS, Brasília, DF.

Recebido em: 17/03/2020

Aprovado em: 17/03/2020
$\Lambda$ Síndrome de Fournier (SF) foi incialmente exposta no século XV a.c. por Hipócrates devido à complexidade da erisipela. Trata-se de uma doença infecciosa grave onde os tecidos moles são atingidos, com um avanço acelerado para as áreas das genitálias e adjacentes, ocorrendo uma destruição tissular intensa. Nos homens tem início no escroto e pênis, e nas mulheres vulva e virilha. Conhecida também por gangrena de escroto, idiopática, fulminante, sinérgica, fasceíte necrosante ou ainda celulite necrosante sinérgica ${ }^{(1-4)}$.

Etiologicamente esta síndrome é polimicrobiana com envolvimento de micro- organismos aeróbicos e anaeróbicos nos quais provocam trombose final de pequenos vasos subcutâneos e, consequentemente, necrose local. Evolui rapidamente tornando-se potencialmente mortal. Por se tratar de uma infecção de início agudo, há evidências de pequenos casos relatados em genitálias femininas e pessoas com idade inferior aos $15 \operatorname{anos}^{(2,3,5)}$.

Homens entre trinta e sessenta anos são os grupos mais acometidos por essa síndrome. Comorbidades tais como: diabete mellitus - DM (presente em 32-66\% dos acometidos), desnutrição, déficits neurológicos, doenças renais, doenças hepáticas, imunossupressores, síndrome da imunodeficiência adquirida (SIDA), uso abusivo de drogas e dentre outras são as mais ligadas a essa patologia ${ }^{(1,6)}$. 
De acordo com estudo ${ }^{(1)}$, no Brasil, para cada 10 homens um é acometido pela síndrome, esta que possui uma alta taxa de prevalência. Qualquer idade pode ser atingida, porém a média é por volta dos 50 anos. A mesma possui altos índices de letalidade, com uma variação entre 13 a 30,8\% no país. Também é uma questão de saúde pública, levando em consideração a ocorrência, prevalência, letalidade, tratamento, reabilitação e os custos elevados. Entretanto, em uma análise de dados do departamento de informática do Sistema Único de Saúde (DATASUS), em requerimentos de internação hospitalar para tratamento dos pacientes acometidos por tal síndrome, foram num total 8.924 autorizações de internações hospitalares aprovadas (AIH) de janeiro a junho de 2019 em hospitais públicos do Brasil $^{(7)}$.

É de suma importância que os pacientes acometidos pela SF sejam acompanhados precocemente pelas equipes multiprofissionais da saúde, a fim de diminuir as complicações e, por conseguinte, evitar que a morte seja impedida. Certifica-se que a mesma possui uma mortalidade com cerca de 40 a $67 \%$ dos pacientes acometidos, o diagnóstico e tratamento de forma precoce fazem com que esses índices diminuam ${ }^{(2)}$.

Com o propósito de alcançar a eficácia na Sistematização da Assistência de Enfermagem (SAE) aos pacientes acometidos pela SF e, de acordo com o estudo(8), os enfermeiros devem utilizar a história clínica e pregressa do paciente para a realização dos diagnósticos de enfermagem podendo, assim, realizar as orientações das intervenções e tomada de decisão, acolhendo o biopsicossocial do paciente durante a sua assistência. Entretanto, estudo $^{(4)}$ afirma que é de suma importância o diagnóstico precoce, o tratamento adequado para a precisão das intervenções na assistência de enfermagem, a enfermagem deve ter um conhecimento amplo acerca da patologia, sendo necessário o exame diário da ferida para verificar a sua evolução, impossibilitando assim os possíveis sinais de complicações da doença.
66

\section{De acordo com} estudo(1), no Brasil, para cada 10 homens um é acometido pela síndrome, esta que possui uma alta taxa de prevalência. Qualquer idade pode ser atingida, porém a média é por volta dos 50 anos. A mesma possui altos índices de letalidade, com uma variação entre 13 a 30,8\% no país. Também é uma questão de saúde pública, levando em consideração a ocorrência, prevalência, letalidade, tratamento, reabilitação e os custos elevados.
A dificuldade de um bom prognóstico da mesma está relacionada ao diagnóstico e tratamento tardio, trazendo sérias complicações ao seu portador ${ }^{(2,8)}$.

Portanto, o objetivo deste trabalho é identificar por meio de revisão bibliográfica o conhecimento e atuação do enfermeiro sobre a SF para que a SAE seja executada de uma forma eficaz, prestando um atendimento eficiente ao paciente. Assim, questiona-se: De acordo com as pesquisas estudadas, o enfermeiro possui o preparo e conhecimento necessários para a execução da SAE para atender o paciente com tal síndrome?

\section{METODOLOGIA}

Tratou-se de uma revisão bibliográfica, cujo modelo de pesquisa utiliza como fonte de informações a bibliografia sob o tema decidido. Esse tipo de averiguação proporciona um resumo das evidências relacionadas a uma estratégica de interferências específicas, mediante a utilização de investigação clara e sistemática de pesquisa, opinião crítica e síntese da comunicação escolhida. Revisões sistemáticas são especialmente úteis para completar as comunicações de um conjunto de análises ocorridas individualmente conforme estabelecida terapia/ assistência, pois consegue expor soluções incompatíveis ou ainda coincidentes, também reconhecer temas que exijam indícios, ajudando na direção para pesquisas futuras ${ }^{(9)}$.

Também enquadrou-se como um estudo histórico que, de acordo estudo ${ }^{(10)}$, está focado em investigar acontecimentos ou instituições do passado, tendo como verificação a sua influência na sociedade atual, considerando ser fundamental o entendimento de suas raízes tendo uma visão para a compreensão de sua natureza e função.

A pesquisa foi realizada em banco de dados on-line disponíveis nos acervos bibliográficos na Biblioteca Virtual de Saúde (BVS), do Centro Latino-Americano e do Caribe de Informação em Ciências da Saúde (BIREME), da Scientific Electronic Library Online (SciELO), do Literatura La- 
tino-Americana e do Caribe em Ciências da Saúde (LILACS), da Medical Literature Analysis and Retrieval System Online (MEDLINE) e da National Library of Medicine/ NLM (PUBMED). Os descritores utilizados para a pesquisa foram: "síndrome, Fournier", "necrosante", "enfermagem" e "ferida". A pesquisa foi realizada no período de fevereiro a setembro de 2019. Foi encontrado o total de 23 artigos. Os critérios de inclusão foram: arti- gos publicados entre 2009 a 2019, textos com o resumo; textos completos on-line com disponibilidade gratuitamente; disponíveis no idioma em português para uma análise mais específica, contudo artigos em inglês e espanhol com tradução também foram selecionados. Os critérios de exclusão foram: artigos disponíveis apenas em resumo, material que não abordava o objetivo proposto, ano de publicação inferior a 2009, artigos de língua estrangeira sem tradução. Ao final obteve-se um total de 12 artigos selecionados.

\section{RESULTADOS}

Após analisar todo o material selecionado, foram gerados dados para a construção de um quadro contendo informações pertinentes de cada artigo, tais como: título, autores, ano de publicação, objetivo do artigo e resultados (Quadro 1).

Quadro 1. Artigos selecionados nos bancos digitais. Brasilia, DF, Brasil, 2019

\begin{tabular}{|c|c|c|c|c|}
\hline Título do Artigo & Autores & Ano & Objetivo & Resultado \\
\hline $\begin{array}{l}\text { Síndrome de Fournier: } \\
\text { Análise dos fatores de } \\
\text { mortalidade. }\end{array}$ & $\begin{array}{l}\text { CANDELA- } \\
\text { RIA et al. }\end{array}$ & 2009 & $\begin{array}{l}\text { Avaliar os fatores relacionados } \\
\text { com mortalidade. }\end{array}$ & $\begin{array}{l}\text { Sobreviveram } 33 \text { dos doentes e houve } 10 \text { ( } 23,2 \%) \\
\text { óbitos. A letalidade relacionou-se a pacientes mais } \\
\text { velhos, tempo de evolução longo, internações cur- } \\
\text { tas, índices fisiológicos apache II elevado, sepse e } \\
\text { broncopneumonia. }\end{array}$ \\
\hline $\begin{array}{l}\text { Síndrome de Fournier: } \\
10 \text { Anos de avaliação }\end{array}$ & $\begin{array}{l}\text { DORNELAS } \\
\text { et al. }\end{array}$ & 2012 & $\begin{array}{l}\text { Realizar estudo retrospectivo, ba- } \\
\text { seado na análise de prontuários } \\
\text { médicos de } 23 \text { pacientes portado- } \\
\text { res de síndrome de Fournier. }\end{array}$ & $\begin{array}{l}\text { As técnicas de reparação cutânea foram eficientes e } \\
\text { a reparação escrotal foi também efetiva em todos os } \\
\text { casos, obtendo-se bons resultados estéticos. Houve } \\
3 \text { óbitos (13\%), } 2 \text { deles, em pacientes com doenças } \\
\text { pregressa e portadores de comorbidades. }\end{array}$ \\
\hline $\begin{array}{l}\text { Relato de Caso: Sín- } \\
\text { drome de Fournier } \\
\text { após implantação de } \\
\text { sling transobturatório }\end{array}$ & SILVA et al. & 2013 & $\begin{array}{l}\text { Relatar o caso de um paciente com } \\
\text { diagnóstico de distopia vesical } \\
\text { grau II que evolui com gangrena } \\
\text { de Fournier, após cirurgia para im- } \\
\text { plantação transobturatória de sling } \\
\text { sintético de marlex, no Hospital Re- } \\
\text { gional de sobradinho-DF, visando } \\
\text { discutir os aspectos relacionados á } \\
\text { infecção do sitio cirúrgico. }\end{array}$ & $\begin{array}{l}\text { A paciente do presente estudo evoluiu, após rein- } \\
\text { tervenção cirúrgica e medicamentosa, com melhora } \\
\text { progressiva, recebendo alta no } 38^{\circ} \text { dia após a co- } \\
\text { locação de sling, com orientação para acompanha- } \\
\text { mento ambulatorial. }\end{array}$ \\
\hline $\begin{array}{l}\text { As abordagens atuais da } \\
\text { Gangrena de Fournier }\end{array}$ & OZKAN et al. & 2014 & $\begin{array}{l}\text { Analisar a demografia, caracterís- } \\
\text { tica clínica e abordagens e trata- } \\
\text { mento, bem como os resultados } \\
\text { da gangrena de Fournier. }\end{array}$ & $\begin{array}{l}\text { As características demográficas e clinicas dos pacien- } \\
\text { tes foram evidenciadas em uma tabela. As origens } \\
\text { etiológicas foram abcesso perianal em cinco pacientes } \\
(41,6 \%) \text {, tumores retais em dois pacientes }(16,6 \%) \text {, } \\
\text { abcesso de Bartholin em um paciente }(8,3 \%) \text {, abcesso } \\
\text { vulvar em um paciente }(8,3 \%) \text {, tratamento com enema } \\
\text { esteroide para colite ulcerativa em um paciente }(8,3 \%) \text {, } \\
\text { hidradenite supurativa em um paciente }(8,3 \%) \text {, e ne- } \\
\text { nhum fator etiológico foi identificado em um paciente. }\end{array}$ \\
\hline $\begin{array}{l}\text { Evidências científicas } \\
\text { brasileiras sobre gan- } \\
\text { grena de Fournier }\end{array}$ & $\begin{array}{l}\text { SANTOS } \\
\text { et al. }\end{array}$ & 2014 & $\begin{array}{l}\text { Descrever os registros científicos } \\
\text { brasileiros publicados nos últimos } \\
\text { vinte anos acerca da gangrena de } \\
\text { Fournier. }\end{array}$ & $\begin{array}{l}\text { De acordo com os artigos encontrados, os principais } \\
\text { sintomas da gangrena de Fournier incluem descon- } \\
\text { forto com sensações dolorosa, febre elevada, ede- } \\
\text { ma, mal-estar e sudorese. Na maior parte dos ca- } \\
\text { sos são observados eritema e formação de bolhas, } \\
\text { evoluindo para uma ferida. O quadro clínico auxilia } \\
\text { na seleção da terapêutica antimicrobiana empírica } \\
\text { antes mesmo do resultado da cultura. }\end{array}$ \\
\hline
\end{tabular}




\begin{tabular}{|c|c|c|c|c|}
\hline $\begin{array}{l}\text { Síndrome de Fournier: } \\
\text { Diagnósticos de En- } \\
\text { fermagem segundo a } \\
\text { NANDA }\end{array}$ & $\begin{array}{l}\text { CORDEIRO } \\
\text { et al. }\end{array}$ & 2014 & $\begin{array}{l}\text { Estudo de caso para avaliação de } \\
\text { um indivíduo do sexo masculino, } 31 \\
\text { anos, no pós-operatório de desbri- } \\
\text { damento de Síndrome de Fournier } \\
\text { em região inguinal e coxa esquerda. }\end{array}$ & $\begin{array}{l}\text { Os diagnósticos de enfermagem com base na história } \\
\text { clínica e pregressa do paciente foram usados pelos } \\
\text { enfermeiros para orientar as intervenções de enfer- } \\
\text { magem e tomada de decisões durante a assistência, } \\
\text { atendendo as necessidades do paciente. }\end{array}$ \\
\hline $\begin{array}{l}\text { Sistematização da assis- } \\
\text { tência de enfermagem } \\
\text { a um paciente com sín- } \\
\text { drome de Fournier }\end{array}$ & $\begin{array}{l}\text { PEREIRA } \\
\text { et al. }\end{array}$ & 2015 & $\begin{array}{l}\text { Identificar a influência que a Siste- } \\
\text { matização da Assistência de Enfer- } \\
\text { magem - SAE causa em um pacien- } \\
\text { te com de síndrome de Fournier }\end{array}$ & $\begin{array}{l}\text { Sistematizar e aplicar o cuidado humanizado foram } \\
\text { pontuados como os problemas, diagnósticos, planos } \\
\text { de cuidados, resultados e avaliação de enfermagem } \\
\text { para o melhor aprofundamento do caso em questão. }\end{array}$ \\
\hline $\begin{array}{l}\text { Síndrome De Fournier: } \\
\text { Percepção do sujeito } \\
\text { em relação à experi- } \\
\text { ência com a doença }\end{array}$ & BRITO et al. & 2016 & $\begin{array}{l}\text { Conhecer a percepção dos sujeitos } \\
\text { que desenvolveram a Síndrome } \\
\text { de Fournier quanto à experiência } \\
\text { com a doença }\end{array}$ & $\begin{array}{l}\text { Os sujeitos demostraram ter uma pequena noção da } \\
\text { causa, evolução da doença e o tratamento realizado. } \\
\text { Experimentaram mudanças em seu cotidiano, senti- } \\
\text { mento de vergonha, repulsa e impotência, entre outros. }\end{array}$ \\
\hline $\begin{array}{l}\text { Gangrena de Fournier: } \\
\text { Revisión de facto- } \\
\text { res determinantes de } \\
\text { mortalidade (Gangre- } \\
\text { na de Fournier: Revi- } \\
\text { são dos determinantes } \\
\text { da mortalidade: uma } \\
\text { revisão de literatura) }\end{array}$ & $\begin{array}{l}\text { CAMARGO, } \\
\text { GARCÍA } \\
\text { PERDOMO }\end{array}$ & 2016 & $\begin{array}{l}\text { Descrever os fatores prognósticos } \\
\text { de mortalidade relatados na litera- } \\
\text { tura mundial. }\end{array}$ & $\begin{array}{l}\text { Apesar dos avanços cirúrgicos e cuidados pós-opera- } \\
\text { tórios, a gangrena de Fournier continua a ter altas } \\
\text { taxas de mortalidade, possivelmente devido à falta } \\
\text { de um consenso sobre as taxas de mortalidade ou } \\
\text { fatores prognósticos. O índice de Laor permanece de } \\
\text { grande valor prognóstico, conforme evidenciado pe- } \\
\text { los diferentes autores citados. São necessários estu- } \\
\text { dos que validem o índice de Laor em nosso ambiente, } \\
\text { bem como determinem quais parâmetros possuem } \\
\text { alto valor preditivo, a fim de simplificar o índice. }\end{array}$ \\
\hline $\begin{array}{l}\text { Produção Científica so- } \\
\text { bre Gangrena de Four- } \\
\text { nier e os cuidados de } \\
\text { enfermagem: Revisão } \\
\text { Integrativa }\end{array}$ & $\begin{array}{l}\text { CRUZ, } \\
\text { ANDRAD E, } \\
\text { ARRUDA }\end{array}$ & 2016 & $\begin{array}{l}\text { Descrever as características da pro- } \\
\text { dução científica em saúde sobre a } \\
\text { gangrena de Fournier em ênfase } \\
\text { nos cuidados de enfermagem }\end{array}$ & $\begin{array}{l}\text { o diagnóstico precoce, o tratamento adequado e a } \\
\text { assistência de enfermagem com intervenções pre- } \\
\text { cisas garantem um melhor prognóstico e para isso } \\
\text { a equipe de enfermagem deverá ter pleno conheci- } \\
\text { mento da doença. }\end{array}$ \\
\hline $\begin{array}{l}\text { Terapêutica Cirúrgica } \\
\text { na Síndrome de Four- } \\
\text { nier: Relatos de Caso }\end{array}$ & $\begin{array}{l}\text { MOREIRA } \\
\text { et al. }\end{array}$ & 2017 & $\begin{array}{l}\text { Relatar um caso de Síndrome de } \\
\text { Fournier em um paciente de } 52 \\
\text { anos e discutir a melhor abordagem } \\
\text { cirúrgica e seus impactos no suces- } \\
\text { so terapêutico nesta enfermidade }\end{array}$ & $\begin{array}{l}\text { Diagnóstico e intervenção precoce, com antibiotico- } \\
\text { terapia de largo espectro e drenagem ampla, per- } \\
\text { mitiu melhores resultados nestes doentes. A morta- } \\
\text { lidade permanece elevada quando o diagnóstico é } \\
\text { tardio e o tratamento operatório retardado. }\end{array}$ \\
\hline $\begin{array}{l}\text { Perfil dos pacientes com } \\
\text { gangrena de Fournier e } \\
\text { sua evolução clínica }\end{array}$ & $\begin{array}{l}\text { DOS SANTOS } \\
\text { et al. }\end{array}$ & 2018 & $\begin{array}{l}\text { Analisar o perfil dos pacientes } \\
\text { com gangrena de Fournier trata- } \\
\text { dos, em um hospital público terci- } \\
\text { ário do oeste de Paraná. }\end{array}$ & $\begin{array}{l}\text { Todos os pacientes apresentaram algum sinal clínico } \\
\text { como dor, abaulamento, eritema, entre outros, e } 38 \\
(95 \%) \text { tinham comorbidades associadas, sendo as } \\
\text { mais comuns diabetes mellitus tipo } 2 \text { e hipertensão } \\
\text { arterial sistêmica. A maioria apresentava como etio- } \\
\text { logia provável abscesso perianal. Todos os pacientes } \\
\text { foram submetidos à antibioticoterapia e tratamento } \\
\text { cirúrgico. Nove pacientes morreram. Houve forte } \\
\text { correlação entre a presença de sepse na admissão } \\
\text { e mortalidade. }\end{array}$ \\
\hline $\begin{array}{l}\text { Relato de caso: trata- } \\
\text { mento da gangrena } \\
\text { de Fournier na cintura } \\
\text { escapular }\end{array}$ & FILHO et al. & 2018 & $\begin{array}{l}\text { Relatar um caso de gangrena de } \\
\text { Fournier que envolveu a região da } \\
\text { cintura escapular após fratura fe- } \\
\text { chada da clavícula e discutir essa } \\
\text { incomum evolução. }\end{array}$ & $\begin{array}{l}\text { A gangrena de Fournier é uma lesão agressiva e } \\
\text { necessita de diagnóstico precoce (correlação clínico- } \\
\text {-laboratorial) com adequada abordagem cirúrgica e } \\
\text { estabilização clínica. }\end{array}$ \\
\hline
\end{tabular}


Fisiopatologicamente, a SF é determinada por qualquer contaminação polimicrobiana onde haverá uma proliferação de tecido fibroso, conhecida como endarteríte obliterante, podendo conduzir à trombose de vasos cutâneos e subcutâneos e, consequentemente, necrose do tecido. Nesse processo infeccioso, acontece de forma sinérgica a ação entre bactérias aeróbicas e anaeróbicas, cooperando e contribuindo sob diversos mecanismos de acesso ao trato urogenital, trato digestório e doenças de pele. De formas isoladas essas bactérias jamais serão patogênicas, embora agrupadas e em ambiente favorável consigam conduzir ao quadro descrito ${ }^{(2,6)}$.

À medida que acontece a difusão de bactérias aeróbicas e anaeróbicas, ocorre a redução da concentração de oxigênio. A hipóxia e isquemia tecidual prejudicam o metabolismo, promovendo elevada propagação de micro-organismo facultativo, que se utiliza das fontes enérgicas das células, principalmente nas primeiras 48 a 72 horas de infecção(4).

Pacientes com essa patologia comumente seguem um quadro clínico característico, ou seja: dois a sete dias com febre, necrose cutânea e crepitação, dor intensa, calafrios, edema, eritema, cianose, secreção com odor fétido e repugnante no leito da ferida, flictenas e até crostas em bolsa escrotal e períneo, podendo alcançar a parede abdominal e início da coxa, tendo casos diagnosticados por sepse como complicações ${ }^{(2,6,11)}$.

Faz-se necessário o diagnóstico precoce e tratamento apropriados juntamente com intervenções específicas da assistência de enfermagem. Entretanto, o exame diário da lesão torna-se essencial, o conhecimento acerca da patologia por parte do enfermeiro é indispensável, caso isso não ocorra, a identificação de possíveis sinais de complicações da doença não estará totalmente esclarecida. Propõe-se um seguimento constante com enfermeiro para o acompanhamento do progresso clínico da síndrome e atendimento personalizado ao paciente com prejuízo da integridade cutânea ${ }^{(4)}$.
O exame físico é a principal base para o diagnóstico, contudo, métodos de imagens, como radiografia, ultrassonografia entre outros, cooperam com a validação, considerando o tamanho das lesões, presença de qualquer causa subjacente (motivo oculto não explícito) e avaliando a resposta terapêutica. É de extrema relevância que as equipes multiprofissionais de saúde assistam de maneira precoce os pacientes com SF, reduzindo a morbimortalidade devido ao elevado índice de morte ocasionado pela doença ${ }^{(2)}$.

Diferenças não específicas podem surgir nos exames de imagem, evidenciando infecção, sem que a doença seja classificada. Investigação radiológica consegue revelar a influência de gás, caso não aconteça crepitação, podendo ocorrer falso-negativos ${ }^{(6)}$.

Exames laboratoriais não são específicos, evidenciando repetidamente anemia, trombocitopenia, hiperglicemia, hipocalemia, hiponatremia, azotemia e hipoalbuminemia. Ocorre alteração dos seguintes exames para a SF: leucocitose com desvio para a esquerda, proteína $\mathrm{C}$ reativa (PCR) aumentada e creatinofosfoquinase (CPK) elevada, há existência de descoberta que insinuam infecção, porém inespecíficos para a doença ${ }^{(6)}$.

O tratamento clínico inicial deve ser individual, deverá ocorrer uma associação de antibioticoterapia de largo espectro com revestimento para os micro-organismos aeróbios e anaeróbios, cuja qual tem pouca eficácia quando empregada individualmente, pois a uma importância da associação ao tratamento cirúrgico, acompanhado de desbridamentos agressivos. Também o cuidado rigoroso com as lesões e acompanhamento multidisciplinar. A SF possui indicação de abordagem clínica e cirúrgica que deve ter início imediato para que seja definida qual será a abordagem definitiva desses pacientes ${ }^{(1,4,6,12)}$.

A conduta cirúrgica torna-se essencial e baseia-se em desbridamento amplo dos tecidos desvitalizados, sendo necessárias diversas reabordagens com o objetivo de interromper a progressão da infecção. Durante essa conduta, torna-se indicada a biópsia da fáscia, por ser apontada como o método padrão ouro para diagnóstico ${ }^{(1,6)}$.

A conduta cirúrgica é imprescindível, abrangendo terapia por oxigenação hiperbárica, que tem apresentado resultados discutíveis no que diz respeito a sua utilidade. Alguns autores defendem a utilização dessa terapia na lesão, em contrapartida, outros defendem a necessidade de estudos mais aprofundados quanto à sua aplicação nos vários tipos de lesões ${ }^{(4)}$.

A cobertura indicada para desbridamento químico do tecido necrótico de modo acelerado e sem traumas da lesão é a papaína, por combater a infecção e agilizar o processo de cicatrização, com influência bactericida, bacteriostática e anti-inflamatória, mostrando ser vantajosa pelo seu baixo custo final ${ }^{(2,4)}$.

Dentre as complicações encontradas, destacam-se: hemorragia cerebral, síndrome da angústia respiratória, coagulopatias, insuficiência renal e cardíaca, pneumonia, disfunção hepática, abscessos disseminados, acidose e extensão da síndrome ao tronco. A septicemia está correlacionada a tais complicações que levam a alterações sistêmicas, levando ao óbito ${ }^{(8,13)}$.

No processo de enfermagem está inserido a $\mathrm{SAE}$, que é uma metodologia científica que busca coletar dados para obter resultados positivos e, assim, o enfermeiro emprega seus conhecimentos técnico-científicos e humanos na assistência aos seus pacientes. Além de realizar o diagnóstico de enfermagem, planejar cuidados, programar e avaliar os resultados esperados. A SAE irá organizar e executar o processo de enfermagem, que norteará o enfermeiro a orientar as equipes com propósito de uma assistência individual e integral, podendo oferecer respaldo científico, segurança e direcionamento para as atividades realizadas ${ }^{(12,14)}$.

A enfermagem possui uma função essencial durante a totalidade do tratamento para a recuperação do indivíduo com SF. Contudo, a patologia exige uma intervenção imediata, esta deverá ser realiza- 
da mediante a identificação do diagnóstico de enfermagem e da implementação precoce, especialmente no que se trata à vigilância das manifestações de infecções e na execução dos curativos, sendo necessário um amplo conhecimento acerca de curativos e coberturas disponíveis no mercado, porque requerer cautelas rigorosas com a habilidade asséptica ${ }^{(12)}$.

\section{DISCUSSÃO}

Os autores ${ }^{(1,5,11)}$ descrevem a SF como uma fasceíte necrosante polimicrobiana que atinge a genitália e áreas adjacentes, além disso, estudo(15) define que a SF se trata de uma infecção infrequente e possui índices de letalidade elevados cujo tecido acometido será o subcutâneo, onde ocorrerá uma rápida progressão da necrose.
De acordo com estudo ${ }^{(11)}$, o panorama médico de sinais e sintomas terá a presença predominante da trilogia que inclui dor, edema e eritema, corroborando com o estudo em questão, porém autores $(2,6)$ acrescentam que há a presença ainda de crepitação, febre e odor fétido.

Os principais fatores de predisposição para o surgimento de tal patologia foram evidenciados no estudo ${ }^{(16)}$ e incluem: diabete mellitus, desnutrição, tabagismo, alcoolismo, doenças imunossupressoras e síndrome da imunodeficiência adquirida. Novos fatores que não foram informados em outras pesquisas, como: idade avançada e hospitalização prolongada ${ }^{(13)}$.

A atuação do enfermeiro não foi bem esclarecida na maior parte dos artigos da pesquisa, no entanto, auto- res $^{(8,12)}$ descrevem que a atuação do enfermeiro deverá condizer com relação aos cuidados com a ferida, o surgimento de novas superfícies necrosadas e indícios de infecções; como também: administrar antibioticoterapia, monitorar a glicemia, os sinais vitais e a septicemia, instalar colchão piramidal, realizar o reposicionamento corporal, ofertar dieta balanceada rica em fibras, ter precaução com acesso venoso periférico, orientar atividades físicas de extensões balanceadas e informar a vítima e familiares acerca da patologia, os cuidados apropriadas com a lesão e da conservação da saúde mental e física para o bom prognóstico clínico.

Com base nesses dados, estabeleceu-se um plano de cuidados para o paciente com SF (Quadro 2):

\section{Quadro 2. Plano de cuidados para o paciente com Síndrome de Fournier. Brasilia, DF, Brasil, 2019}

Diagnósticos de Enfermagem

Perfusão tissular periférica ineficaz relacionada ao conhecimento insuficiente sobre os fatores modificáveis caracterizada por edema e alteração em característica da pele.

Risco de volume de líquidos desequilibrados associado à sepse.

\section{Intervenções de Enfermagem/Justificativas}

\section{1-Verificar sinais flogísticos.}

Devido ao processo infeccioso com localização na região perineal e adjacências pode ter presença de dor, febre, edema ou evoluir para necrose, este que é um quadro com muitas dificuldades até para os profissionais de saúde, ocorrendo um agravo da ferida fazendo que ocorra o acesso da microbiota residente de derme com disseminação de bactérias anaeróbicas e aeróbicas ${ }^{(12)}$.

2-Realizar curativo na área lesada.

As necessidades dos curativos e outras terapias de tratamento devem ser realizadas no momento da internação tanto quanto no cuidado em casa, que irá ocorrer uma mudança na rotina do paciente e sua família ${ }^{(2)}$.

1-Monitorar sinais de sepse (Temperatura $>38,5^{\circ}$ ou $<37,0^{\circ}$; Eliminação urinária diminuída; Taquicardia e taquipnéia; pele pálida e fria; leucócitos e bactérias na urina e cultura positiva do sangue) A natureza invasiva de dispositivo de acesso venoso coloca o cliente em risco de infeções oportunistas e de sepse. A sepse causa vasodilatação maciça e a resultante hipovolemia, levando a hipóxia do tecido e à diminuição das funções cardíacas e renais. A resposta compensatória do organismo aumentar a frequência respiratória $e$ cardíaca, em uma tentativa de corrigia a e hipóxia e a acidose ${ }^{(17)}$.

2- Monitorar os sinais e sintomas de desequilíbrio eletrolítico: Hipercalemia (Ex: pulso irregular ou disritmias como contrações ventriculares prematuras), Hipocalemia (Ex: Modificações no eletrocardiograma, como a inversão da onda T, e a depressão ST) e Hiponatremia (Ex: Letargia, coma e dor abdominal).

A atividade da bomba sódio-potássio e alterada devido à hipóxia. Se a quantidade líquidos e inadequada, ou o fluxo sanguíneo renal esta comprometido, os níveis de potássio elevam-se. A hipocalemia e vista com mais frequência devido à maior conscientização sobre a adequada posição de líquidos. As perdas de sódio resultam das áreas desprotegidas de pele e das trocas para os espaços intersticiais durante os períodos de permeabilidade capilar aumentada, causando pela osmose mudanças no sensório, fraqueza e câimbras musculares ${ }^{(17)}$. 
Risco da dignidade humana comprometida

Distúrbio na identidade pessoal relacionado a preconceito percebido caracterizado por alteração da imagem corporal.

Baixa autoestima situacional relacionada à alteração da imagem corporal caracterizada a subestima a capacidade de lidar com a situação.

Recuperação cirúrgica retardada relacionada à dor caracterizada por mobilidade prejudicada e procedimento cirúrgico extenso.

Risco de choque associado à sepse.

Integridade tissular prejudicada relacionada a conhecimento insuficiente sobre proteção da integridade tissular caracterizada por tecidos destruídos e dano tecidual.
1- Solicitar e encaminhar ao setor de psicologia e serviço social.

A orientação sobre a patologia deve ser clara e objetiva a fim de esclarecer os cuidados com a lesão e a manutenção da saúde psicossocial do paciente ${ }^{(12)}$.

2- Orientar familiares quanto à necessidade de apoio dos mesmos.

Pacientes que foram acometidos por tal síndrome, descreviam ter aversão ao olhar ou tocar no curativo, não havendo expressão de vontade de pelo menos olhar a lesão logo após o Desbridamento(2).

1- Encorajar o paciente ao enfretamento a alteração da sua imagem corporal modificada. Visto que o paciente experimenta o sentimento de medo e isolamento devido a sua autoimagem ter sido modificado ${ }^{(2)}$.

2- Solicitar de parecer ao serviço de psicologia.

É de suma importância da equipe de saúde de alguma forma considerar as particularidades do paciente com SF, conhecer e desenvolver nova percepção do paciente quanto à doença (2)

1-Encorajar o cliente a expressar os sentimentos sobre as modificações na aparência corporal. 0 compartilhar de preocupações promove a confiança e permite o esclarecimento de conceitos errados ${ }^{(17)}$.

2- Discutir e sugerir as maneiras pelas quais o cliente pode enfrentar as mudanças na imagem corporal: cobrir o curativo, mudar o curativo frequentemente para a prevenção de odores, planejar as atividades que exigem ficar de pé ou caminhar para o inicio da manha.

As lesões abertas, drenando e com odor fétido são desagradáveis aos outros. Ensinar o cliente a controlar o odor e a aparência das lesões promove a melhoria do autoconceito e da imagem corporal ${ }^{(17)}$.

1- Realizar curativos.

A enfermagem possui um importante papel no que diz respeito a reabilitação do paciente, em todo o tempo de tratamento, em especial no que diz respeito aos sinais e sintomas da infecção, com foco na realização de curativos ${ }^{(12)}$.

2- Administrar analgésico conforme prescrição médica para alívio dar dor. 0 ritmo apropriado da administração otimiza a dor eficácia da medicação para a dor ${ }^{(17)}$.

1-Realizar troca de acesso venoso periférico para evitar complicações: febre, sensibilidade, edema e secreção no local, oclusão do dispositivo do acesso venoso, incapacidade de infusão, flebite.

A compreensão dos sinais e sintomas de complicações permite a detecção precoce visando uma intervenção oportuna. A febre e as modificações no local da inserção podem indicar infecção. A velocidade incorreta de infusão ou a incapacidade de infundir devido a pontos de obstrução ou dano ao cateter. 0 edema facial pode indicar a síndrome da veia cava superior. A flebite tem sido observada em 12,5 a $23 \%$ dos pacientes com vias de cateter venoso central de inserção periférica (CCIP) (17). 2-Administrar antibióticos profiláticos conforme prescrição médica e monitorar sinais e sintomas de sepse (Temperatura $>38,5^{\circ}$ ou $<37,0^{\circ}$; Eliminação urinária diminuída; Taquicardia e taquipnéia; pele pálida e fria; leucócitos e bactérias na urina e cultura positiva do sangue). Os organismos Gram- positivo e negativo podem invadira as feridas abertas; os pacientes debilitados são mais vulneráveis. A reação à sepse resulta em vasodilatação generalizada om hipovolemia, tendo como consequência a hipóxia do tecido e a diminuição da função renal e do debito cardíaco. Isto, por sua vez, desencadeia uma reação compensatória de aumento das frequências cardíaca e respiratória visando à correção da hipóxia e da acidose. As bactérias na urina ou no sangue indicam infeção(17).

\section{1- Realizar reposicionamento corporal rigoroso.}

A técnica apropriada previne dano ao aparelho e lesões nas articulações. Mudanças de posição a cada duas horas reduz ainda mais o risco do paciente par desenvolver a lesão por pressão ${ }^{(17)(18)}$.

2- Verificar sinais de infecção da ferida.

Os sinais de dor, ardência e odor proveniente da ferida. Estes sinais e sintomas podem indicar que a lesão esta em processo de infecção ${ }^{(17)}$. 
A SAE tem como método a organização e sistematização do cuidado com alicerce nos princípios do processo científico. A objetividade é o reconhecimento das condições do processo saúde-doença e as necessidades de cuidados de enfermagem, auxiliando nas intervenções de promoção, prevenção, recuperação e reabilitação da saúde do indivíduo, família e comunidade. Esse método é uma ferramenta privativa de trabalho do enfermeiro conforme o Artigo $4^{\mathrm{a}}$ da Resolução n. ${ }^{\circ}$ 358/2009 do Conselho Federal de Enfermagem (COFEN): "Incumbe a liderança na execução e avaliação do processo de enfermagem, de modo a alcançar os resultados de enfermagem esperados, cabendo-lhe, privativamente, o diagnóstico de enfermagem" ${ }^{\prime \prime 19,20)}$.

Assim, houve uma enfatização que é essencial que o processo de enferma- gem esteja implementado, visto se tornar indispensável à utilização de uma ferramenta que auxiliará o enfermeiro na maneira do cuidar do paciente em tais situações clínicas ao inicializar a assistência de enfermagem ${ }^{(21)}$

\section{CONCLUSÃO}

Entende-se que a SF, por ser uma doença de rápida progressão, exige a necessidade da inserção do enfermeiro na rotina dos cuidados ao paciente, uma vez que esses profissionais passam maior parte do tempo com esses indivíduos, implementando a assistência de enfermagem para sua reabilitação.

Após uma revisão da literatura, verificou-se que a SF possui uma ampla divulgação, porém ainda encontra-se pouco estudo dos cuidados de enfermagem para um melhor esclarecimento da atuação do enfermeiro, percebeu-se ainda que há uma deficiência quanto ao diagnóstico e tratamento adequado para a aplicabilidade da SAE aos pacientes portadores de tal síndrome. Foram analisados na totalidade de 13 artigos, 05 artigos descreviam a atuação do enfermeiro para tal patologia.

Por esse motivo, conclui-se que, de acordo com a revisão bibliográfica, não há dados publicados suficientes para a efetiva análise do conhecimento do enfermeiro frente à SF, o que torna-se imprescindível a conscientização de toda equipe de enfermagem com palestras, estudos de casos, evolução clínica e treinamentos específicos nos cuidados com o portador da patologia. Espera-se que este estudo possa contribuir para o interesse de novos artigos sobre o papel do enfermeiro no diagnóstico e aplicabilidade da SAE.

\section{Referências}

1.Santos DR, Roman ULT, Westphalen AP, Neto ACS.

Profile of patients with Fournier's gangrene and their clinical evolution. Revista do Colégio Brasileiro de Cirurgiões. 2018 fev; 45(1). 2.Brito RS, Rodrigues PASSJ, Coqueiro JM. Síndrome de Fournier: percepção dos sujeitos em relação à experiência com a doença. Revista de Enfermagem: UFPE on-line. 2016 set; 4(10):3601-3607. 3.Ozkan OF, Koksa N, Altinli E, Celik A, Usunn MA, Cikman O, Ergun E, Kiraz HA, Karaayvaz M. Fournier's gangrene current approaches. International Wound Journal. 2014 ago; 13(5):713-716.

4. Santos EI, Vale ILVV, Reis ICPM, Neves PB, Pontes CM, Camara SGC. Brazilian scientific evidence on Fournier's gangrene. Revista da Rede de Enfermagem do Nordeste. 2014 dez; 15(6):1047-1055. 5. Camargo L, García-Perdomo HAC. Gangrena de Fournier: revisión de factores determinantes de mortalidad. Revista Chilena de Cirurgia. 2016 mai; 68(3):273-277.

6. Silva HYW, Moura TR, Lopes MR, Neto FC, Damata FR, Barboza GP, Reis LGP, Reis LFA, Oliveira MVS, Soares PS. Relato de caso: Síndrome de Fournier após implantação de sling transobturatório. Comunicação em ciência da saúde. 2013 set; 1(24):77-84.

7. Ministério da Saúde (BR). DATASUS. Procedimentos hospitalares dos SUS por local de internação. Brasília (DF): MS, 2019.

8.Cordeiro TMSC, Freitas GB, Braga VS, Reis TS, Castro TVB. Síndrome de Fournier: diagnósticos de enfermagem segundo a NANDA. Rev Epidemiol Control Infect. 2014 out./dez.; 4(4):262-263.

9.Sampaio RF, Mancini MC . Estudos de revisão sistemática: um guia para a síntese criteriosa da evidência científica. Revista Brasileira de Fisioterapia. 2007 jan./fev.; 11(1):83-89.

10. Prodanov CC, Freitas EC. Metodologia do trabalho científico: métodos e técnicas da pesquisa e do trabalho acadêmico. 2. ed. Rio Grande do Sul: Universidade Feevale; 2013. 36 p.

11. Moreira DR, Gonçalves ALS, Aucelio RS, Silva KG. Terapêutica cirúrgica na síndrome de Fournier: relato de caso. Revista de Medicina. 2017 ju; 96(2):116-120.

12. Cruz RAO, Andrade LL, Arruda AJCG. Produção científica so- bre gangrena de fournier e os cuidados de ernfermagem: revisão integrativa. Revista de Enfermagem: UFPE on-line. 2016 nov; 5(10):4329-4335.

13. Candelária $\mathrm{PAP}<$ Klug WA, Capelhuchnik $\mathrm{P}$, Fang CB. Síndrome de Fournier: análise dos fatores de mortalidade. Revista Brasileira de Coloproctologia. 2009 jun; 29(2):197-202.

14. Tannure MC, Pinheiro AM. SAE: Sistematização da assistência de enfermagem: guia prático. 2.ed. Rio de Janeiro: Guanabara Koogan; 2017.

15. Filho NC, Patriota G, Falcão R, Maia R, Daltro G, Alencar D. Relato de caso: tratamento da gangrena de Fournier na cintura escapular. Revista Brasileira de Ortopedia. 2018 jul; 53(4):493-498.

16. Dornelas MT, Correa DMP, Barra FM, Corrêa LD, Silva EC, Dornelas GC, Corençlas MC. Síndrome de Fournier: 10 anos de avaliação. Revista Brasileira Cirurgia Plástica. 2012 out; 4(27):600-604.

17. Carpenito LJ. Planos de cuidados de enfermagem e documentação: diagnósticos de enfermagem e problemas colaborativos. trad. Ana Maria Vasconcellos Thorell. 2. ed. Porto Alegre: Artmed; 2011. 18. Potter PA, Perry AG. Fundamentos de enfermagem. Rio de Janeiro: Elsevier; 2013.

19. Conselho Federal de Enfermagem (BR). Resolução n. ${ }^{\circ} 358$ de 15 de outubro de 2009. Dispõe sobre a sistematização da assistência de enfermagem e a implementação do processo de enfermagem em ambientes públicos e privados, em que ocorre o cuidado profissional de enfermagem, e dá outras providências. Brasília (DF): COFEN, 2019.

20. Truppel TC, Meier MJ, Calixto RC, Peruzzo SA, Crozeta K. Sistematização da assistência de enfermagem em unidade de terapia intensiva. Revista brasileira de enfermagem. 2009 abr; 62(2):221-227.

21. Pereira MAA, Nobre KM, Paiva ASS, Alves TPA, Paiva AM. Sistematização da assistência de enfermagem em um paciente com síndrome de fournier. Revista Sanare. 2015 jun; 1(14):109. 